\title{
Term Gravid Uterus as a Content of Congenital Umbilical Hernia -A Complication in a Multigravida That Presented in Labour
}

\author{
Adebiyi Gbadebo Adesiyun, Nkeiruka Ameh, Hajaratu Umar-Sullyman, Solomon Avidime, \\ Garba Alkali, Fadimatu Bakari, Rabiatu Aliyu \\ Department of Obstetrics \& Gynaecology, Ahmadu Bello University Teaching Hospital, Zaria, Nigeria \\ Email: biyi.adesiyun@yahoo.com
}

Received 17 November 2014; revised 20 December 2014; accepted 3 January 2015

Copyright (C) 2015 by authors and Scientific Research Publishing Inc.

This work is licensed under the Creative Commons Attribution International License (CC BY).

http://creativecommons.org/licenses/by/4.0/

(c) (i)

\begin{abstract}
Complications arising from neglected umbilical hernia are not uncommon in pregnancy, more especially in developing countries with characteristically poor health seeking behaviour and less encouraging attitude towards surgical intervention for un-complicated medical conditions. The report is on a 34-year-old para 8 who presented with prolonged labour and an irreducible herniated gravid uterus complicating a neglected congenital umbilical hernia. The patient was resuscitated. She had spontaneous vaginal delivery while preparation was being made for an elective caesarean section.
\end{abstract}

Keywords

Umbilical Hernia, Gravid Uterus, Term Pregnancy, Labour

\section{Introduction}

Umbilical hernia is not an uncommon pathology amongst blacks; rate as high as 15\% have been reported among pregnant women in the West African sub-region [1]. Umbilical hernia is reported to be more common in Africa compared to the Western world [2]. Gravid women with co-existing umbilical hernia are at high risk because they are predisposed to a wide spectrum of complications which include miscarriage, preterm labour, antepartum haemorrhage, intra uterine growth restriction and intrauterine fetal death. Other complications are pressure necrosis and ulceration of anterior abdominal wall, incarceration of gravid uterus, uterine rupture, rupture of the 
anterior abdominal wall and death [3] [4]. This case report is on herniation of a gravid uterus into the sac of an umbilical hernia with some attendant complications. Congenital umbilical hernia which is usually asymptomatic, is widely and ignorantly conceive to be devoid of complications by most people in sub-Saharan Africa. In adulthood, most will not bother to seek medical treatment since they grew up to know themselves with it.

\section{Case Report}

A 34-year-old gravida 9, para 8 with 5 children alive presented in labour with 9 months of pregnancy and an umblical swelling which dates back to childhood. She had been in labour at home for about 48 hours and ruptured membranes about 18 hours prior to presentation. Her last child birth was 2 years ago; a macerated stillbirth, she also had 2 childhood deaths. Index pregnancy was unintended and she did not receive any form of antenantal care although the pregnancy was relatively uneventful. All previous pregnancies were unbooked and all deliveries were at home.

On assessment, she was a young woman in distress, dehydrated with temperature of 37.7 degrees centigrade. She was not pale, anicteric and no pedal oedema. The pulse rate was 130 per minute and blood pressure of 140/90 mmHg. The abdomen was pendulous with huge peri-umblical swelling, distended veins and multiple decubitus ulceration discharging purulent effluent (Figure 1 and Figure 2).

Defect in the anterior abdominal wall was estimated to be $30 \mathrm{~cm} \times 30 \mathrm{~cm}$ with the content being the uterus and bowel; not reducible. It was difficult to delineate the fetal parts as such fetal lie and presentation could not be ascertained. Ultrasound scan showed a live singleton fetus with head in the right iliac fossa and the placenta was antero-fundal. Vulva and vagina were normal and cervix could not be reached. A diagnosis of herniated gravid uterus in a term pregnancy was made.

Patient was immediately commenced on resuscitative measures with intravenous fluid, antibiotics, analgesic and anti-hypertensive while preparation was being made for an emergency caesarean section. The general surgeon team reviewed and suggested repair of hernia after the puerperium. She had a spontaneous vaginal delivery of a female fresh stillborn about 2 hours following admission. The puerperium was uneventful. She was

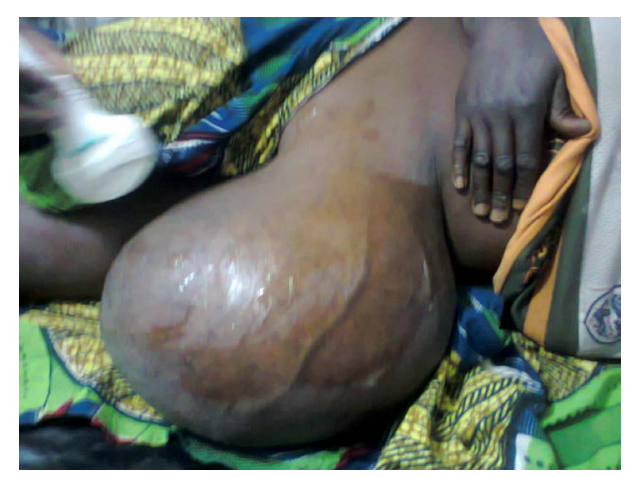

Figure 1. Herniated term gravid uterus with distended veins.

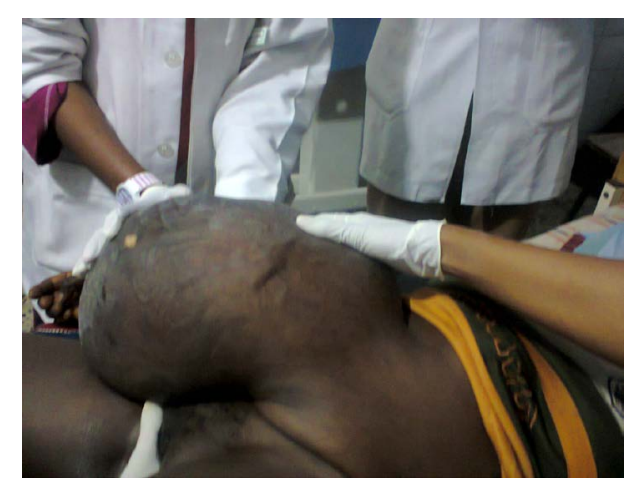

Figure 2. Focus of infected decubitus ulcer. 
booked for elective repair of umbilical hernia by the surgical team. The patient defaulted from follow up.

\section{Discussion}

Umbilical hernia is a common pathology seen in children, and it may be associated with rare life threatening complications like rupture of the hernia and evisceration of urinary bladder [5]. Most umbilical hernia in adulthood are congenital and dates back to childhood, as was the case in the patient reported. In adult, umbilical hernia could also occur from weakened cicatricial tissue closing the umbilical ring [6]. Predisposing factors of adult onset umbilical hernia are pathology that would increase intra-abdominal pressure like obesity, multiple pregnancy, prolonged labour, ascites and large intra-abdominal mass [6] [7]. Surgical treatment for umbilical hernia done in childhood is effective and recurrence is rare [6]. The complication reported in this patient could have been averted if surgical intervention was instituted in childhood; this may not be unconnected to ignorance, poor health seeking behaviour and accessibility to health care services in the developing world. Similar reports in the literature were mainly in multigravida like this case although Mbuagbaw et al. reported a case in a primigravida [8]. Preponderance among multigravida can be explained by repeated pressure effect on the umblical ring resulting in widening ring and laxity of the anterior abdominal wall from pregnancies and labour of previous conceptions and parturition [6] [9]. Besides multigravidity, other factors in this report that may have aided the worsening of this complication, are non enrolment for formal antenatal care in all her pregnancies including the index one, and unsupervised home birth in all her deliveries. Supervision of pregnancy and delivery by trained personnel still remain an insurmountable predicament despite multi-layered governmental and non-governmental multifaceted focused approach in most sub-Saharan Africa settings.

The patient reported presented with prolonged labour, multiple foci of infected anterior abdominal wall decubitus ulceration with an intact skin over umbilical hernia harbouring the gravid uterus, even though authors have reported labour and large infected ulceration on anterior abdominal wall as predisposing factors to rupture of umbilical hernia [6] [10]. Emergency caesarean section was to be the method of delivery in this case, because of prolonged labour and doubt as to the integrity of the anterior abdominal wall to withstand labour in consonant with other reports [11]. This patient however delivered spontaneously per vagina while awaiting caesarean section. Decision to delivery interval by caesarean section has remained a challenge in most resource constrained sub-Saharan health facility mainly from multifactorial reasons. Elective repair of umbilical hernia after the puerperium was the line of management in this case. Elective postpartum repair is favoured because the over stretched abdominal wall that may interfere with repair would have returned to normal, low risk of wound dehiscence and infection and less likelihood of recurrence [12] [13]. On the contrary, some authors prefer to perform herniorrhaphy during caesarean section with no associated wound infection and recurrence [4] [13]. We were not entangled in this controversy because our patient had multiple foci of infected ulceration which would not have allowed concomitant herniorrhaphy during caesarean section. In conclusion, congenital umbilical hernia though a common but asymptomatic surgical condition can be associated with complications, mass dissemination of information especially highlighting the possible complications may be the best way to encourage affected persons to seek treatment.

\section{References}

[1] Punguyire, D., Iserson, K.V. and Apanga, S. (2011) Full-Term Pregnancy in Umbilical Hernia. Pan African Medical Journal, 8, 6. http://dx.doi.org/10.4314/pamj.v8i1.71053

[2] Hernia, D.R. (2000) Principles and Practice of Surgery Including Pathology in the Tropics. In: Badoe, E.A., Archampong, E.Q. and da Rocha-Afodu, J.T., Eds., 3rd Edition, Ghana Publishing Corporation, Tema, 482-502.

[3] Van Rooyen, A.J., Cominos, D.C. and van der Walt, A. (1977) Pressure Necrosis of a Caesarean Section Scar with Exteriorization of the Gravid Uterus: A Case Report. South African Medical Journal, 51, 666-668.

[4] Pandey, A., Kumar, V., Gangopadhyay, A.N. and Upadhyaya, V.D. (2008) Eviscerated Urinary Bladder via Ruptured Umbilical Hernia: A Rare Occurrence. Hernia, 12, 317-319. http://dx.doi.org/10.1007/s10029-007-0302-8

[5] Ahmed, A., Garba, S. and Ukwenya, Y. (2011) Spontaneous Rupture of Umbilical Hernia in Pregnancy: A Case Report. Oman Medical Journal, 26, 285-287. http://dx.doi.org/10.5001/omj.2011.70

[6] Muschaweck, U. (2003) Umbilical and Epigastric Hernia Repair. Surgical Clinics of North America, 83, 1207-1221. http://dx.doi.org/10.1016/S0039-6109(03)00119-1

[7] Mbuagbaw, L.C.E. and Morfaw, F.L. (2012) Gravid Uterus in an Umbilical Hernia. Case Reports in Obstetrics and 
Gynecology, 2012, 439-489.

[8] Hassim, A.M. and Khurana, K.M. (1967) Gravid Uterus in an Umbilical Hernia. Central African Journal of Medicine, 13, 260-261.

[9] Wydell, S.H. (1963) Umbilical Hernia in Pregnancy. British Medical Journal, 5342, 1413-1414. http://dx.doi.org/10.1136/bmj.1.5342.1413-a

[10] Rao, R.S. and Shankaregowda, H.S. (2006) A Case of Herniated Gravid Uterus through a Laparotomy Scar. Indian Journal of Medical Sciences, 60, 154-157. http://dx.doi.org/10.4103/0019-5359.24679

[11] Dare, F.O. and Lawal, O.O. (1991) Experience with 29 Cases of Female Ventral Incisional Hernias in Ile-Ife, Nigeria. International Journal of Gynecology Obstetrics, 36, 29-32. http://dx.doi.org/10.1016/0020-7292(91)90174-4

[12] Adesunkami, A.R. and Faleyinmu, B. (2009) Incidence and Aetiological Factors of Incisional Hernia in a Post Caesarean Operation in a Nigerian Hospital. Journal of Obstetrics Gynaecology, 279, 905-907.

[13] Ochsenbein-Kolble, N., Demartines, N., Ochsenbein-Imhof, N. and Zimmermann, R. (2004) Cesarean Section and Simultaneous Hernia Repair. Archives of Surgery, 139, 893-895. http://dx.doi.org/10.1001/archsurg.139.8.893 
Scientific Research Publishing (SCIRP) is one of the largest Open Access journal publishers. It is currently publishing more than 200 open access, online, peer-reviewed journals covering a wide range of academic disciplines. SCIRP serves the worldwide academic communities and contributes to the progress and application of science with its publication.

Other selected journals from SCIRP are listed as below. Submit your manuscript to us via either submit@scirp.org or Online Submission Portal.
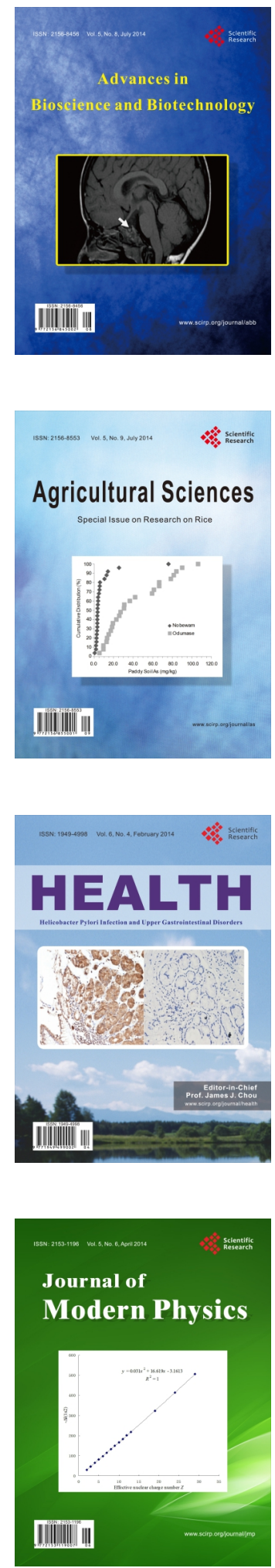
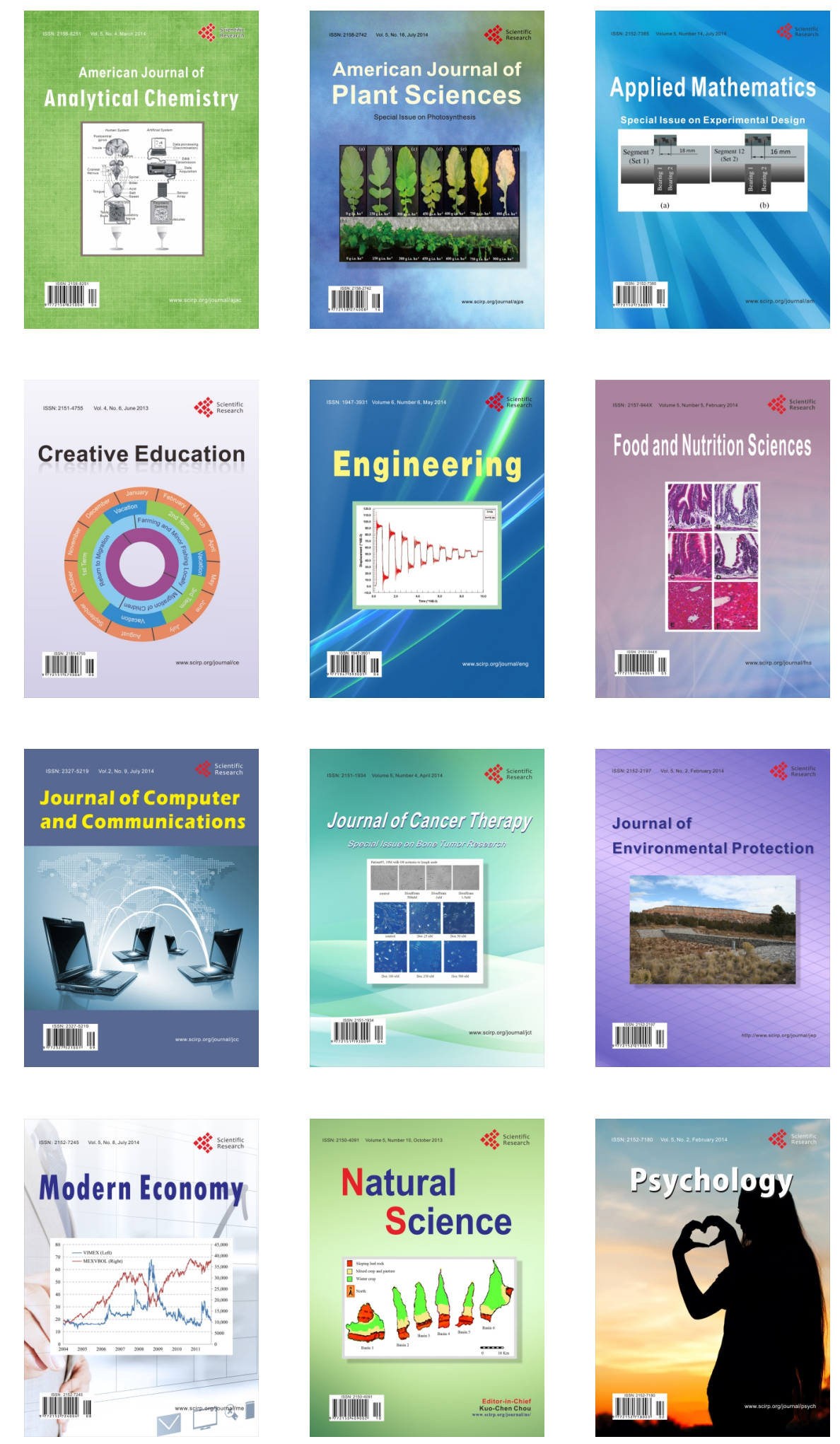